\title{
Automated coronary artery tracking in contrast- enhanced whole-heart coronary magnetic resonance angiography at 3.0T
}

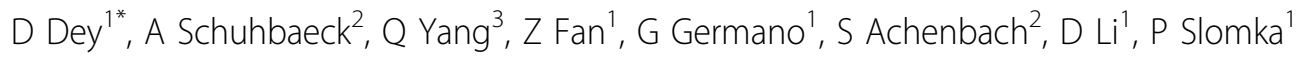

From 16th Annual SCMR Scientific Sessions

San Francisco, CA, USA. 31 January - 3 February 2013

\section{Background}

Contrast-enhanced whole heart coronary Magnetic Resonance Angiography (MRA) at 3.0 Tesla (T) allows noninvasive detection of obstructive stenoses. Automated vessel segmentation and tracking of centerlines is important for quantitative measurement of stenosis, but remains challenging for coronary MRA. We aimed to develop and validate

automated coronary artery segmentation from contrastenhanced whole-heart coronary Magnetic Resonance Angiography at 3.0T.

\section{Methods}

Fifteen patients underwent contrast-enhanced wholeheart coronary MRA using electrocardiograph-triggered,

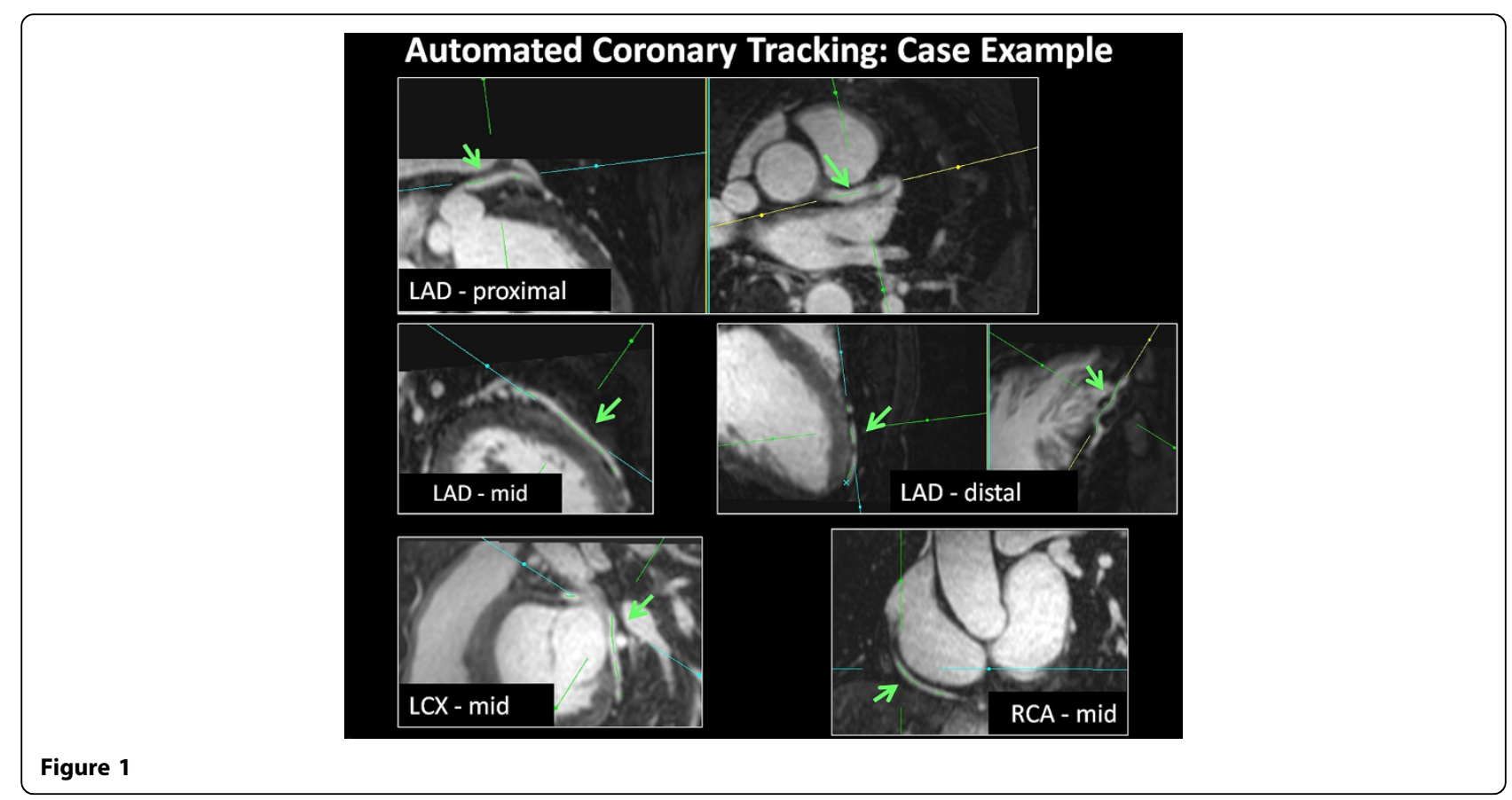

'Biomedical Imaging Research Institute, Cedars-Sinai Medical Center, Los

Angeles, CA, USA

Full list of author information is available at the end of the article

(c) 2013 Dey et al; licensee BioMed Central Ltd. This is an Open Access article distributed under the terms of the Creative Commons 
navigator-gated gradient-echo sequences, at 3.0T, with voxel size of $0.625 \times 0.625 \times 0.9 \mathrm{~mm}$. Automated coronary vessel tracking (AVT) was performed by an algorithm which simultaneously searches for the vascular centerlines and radius, by maximizing a vessel likelihood cost function derived from the directional radial gradients computed from coronary MRA, from a manually placed proximal to a distal end voxel. The algorithm incorporates expected vessel tapering and performs Dijkstrabased search for the optimal path. Forty-five coronary arteries (Left Main and Left Anterior Descending Artery [LM-LAD], Left Circumflex [LCX], Right Coronary Artery [RCA]) were analyzed by the algorithm. An expert reader manually marked the centerlines for all the arteries for comparison. Algorithm performance was evaluated by the Euclidian distance from the expert reader in mm over all arterial centerline points, and also assessed visually by the expert reader on a 3-point grading scale (1-poor, 2-good, 3-excellent).

\section{Results}

The average and maximum 3D distance between the expert and AVT was $0.7 \pm 0.4 \mathrm{~mm}$ and $1.7 \pm 1.5 \mathrm{~mm}$, respectively. The mean visual grade was $2 \pm 1$ in the LMLAD, $3 \pm 1$ in the LCX, and $3 \pm 1$ in the RCA, and $2.5 \pm$ 0.8 overall (see example Figure). AVT was visually judged to be successful (score $>=2$ ) in 99/105 (94\%) proximal and mid coronary artery segments, and 41/45 (91\%) of distal segments; algorithm failure was primarily related to presence of motion artifacts in the corresponding arterial segment.

\section{Conclusions}

We developed an automated coronary vessel tracking algorithm which shows promising results for coronary MRA at 3.0T.

\footnotetext{
Author details

${ }^{1}$ Biomedical Imaging Research Institute, Cedars-Sinai Medical Center, Los Angeles, CA, USA. ²Department of Internal Medicine II, University of Erlangen, Erlangen, Bavaria, Germany. ${ }^{3}$ Department of Radiology, Xuanwu Hospital, Beijing, China.
}

Published: 30 January 2013

doi:10.1186/1532-429X-15-S1-W30

Cite this article as: Dey et al:: Automated coronary artery tracking in contrast-enhanced whole-heart coronary magnetic resonance angiography at 3.0T. Journal of Cardiovascular Magnetic Resonance 2013 15(Suppl 1):W30.
Submit your next manuscript to BioMed Central and take full advantage of:

- Convenient online submission

- Thorough peer review

- No space constraints or color figure charges

- Immediate publication on acceptance

- Inclusion in PubMed, CAS, Scopus and Google Scholar

- Research which is freely available for redistribution

Submit your manuscript at www.biomedcentral.com/submit
C Biomed Central 